IOSR Journal of Pharmacy

e-ISSN: 2250-3013, p-ISSN: 2319-4219, www.iosrphr.org

Volume 2 Issue 6 ||| Nov-Dec. 2012 || | PP.19-24

\title{
Study common plants of medicinal values in sangola taluka of solapur district, Maharashtra (India)
}

\author{
${ }^{1}$ Dr. Tembhurne R. R., ${ }^{2}$ Dr. Nanir S. P. \\ ${ }^{I}$ Dept. of Botany Sangola College, Sangola, Dist.-Solapur \\ ${ }^{2}$ Former Directior Govt. Institute of Science Aurangabad.
}

\begin{abstract}
During the study of the medicinal plants of this region author come across a number of species . In this study five species of medicinal plants are being discussed having great value concern with the medicine which help to cure the various ailment and diseases which inhabiting in the said area. Azadirachta indica Juss., Aloe Vera Mills., Catharanthes roseus Don., Casia fistula Linn., and Emblica officinales Gaertn. are being discussed with respect to scientific name, Vernacular name, family \& distribution, chemical composition and there uses. All species are being reported for the first time as medicinal plants from this region.
\end{abstract}

Keywords-Medicinal plants, Sangola, Maharashtra

\section{INTRODUCTION}

Sangola taluka comes under the Western part of the zone belongs to Solapur district, Maharashtra . Classifying as drought prone areas, shallow and poor type of soil, not retentive of moisture marks this part, along with the scanty and uncertain rainfall, due to scanty and non uniform rains scarcity condition prevail in the talukas . Generally monsoon period is from the second fortnight to June to the end of September bringing rains from South-West monsoon.

Even in the scarcity of water, we selected this region for the study of medicinal plants . Sangola taluka has number of rural areas which are very rich in flora and has geographical distribution. We visited different locality's in the month of June to September ( 2011 ), collected number of samples of leaves, stem , bark , wood, of angiospermic medicinal plants. All these collection was from some rural areas of said area .

In all things there is a poison and there is nothing without a poison. It depends on only upon the dose weather a poison is a poison or not. Medicinal plants have played an essential role in the development of human culture. Many of the modern medicines are produced indirectly from medicinal plants. Plants are directly used as medicines by a majority of cultures around the world. Many food crops have medicinal effects. Medicinal plants are resources of new drugs. Studying medicinal plants helps to understand plant toxicity and protect human and animal from natural poisons. Cultivation and preservation of medicinal plants protect biological diversity.

Plants have always been the main forms of medicine in India and now they are becoming popular throughout the world. People in Europe, America, Australia, Middle East and many other countries outside India are consulting trained herbal professionals and have started using plant medicines. It is estimated that about 70,000 plant species, from algae and angiosperms, have been used medical purposes, because they possess some property or substance, which is medicinally useful. All these plants, commonly known as herbs provide starting material for the isolation or synthesis of conventional drugs.

In the development of modern medicines, biologically active compounds from higher plants have played a very important role in providing essential raw materials. In the beginning of $20^{\text {th }}$ centuary due to the discovery of antibiotics and synthetics medicines, the use of plant medicines declined considerably in many economically developed nations. But because of harmful side effects of synthetic drugs, again about 70 to 80 per cent of the population in the world, started using plant medicine. About 130 drugs, all single chemical entities, originally extracted from higher plants are in current use in modern medicines.

The 'herbal drugs' or 'phytomedicine' are generally single plant extracts and they differ from pure synthetic chemical medicine call 'molecular drugs'. The herbal drugs are mainly used in the form of indigenous ayurvedic medicine, while purely chemical molecular drugs and synthetic drugs prepared after knowing the basic structure of herbal drug are used in the form of allopathic medicines. Indigenous or traditional knowledge refers to the long standing traditions and practices of certain regional, indigenous or local communities. Indigenous knowledge also encompasses the wisdom, knowledge and teaching of these communities. In many 
cases indigenous knowledge has been orally passed for generations from person to person. Some forms of traditional knowledge are expressed through stories, legends, folklore, rituals, songs, and even through the laws that shape that land (Acharya and Shrivastava, 2008).

All medicinal plants have curative properties due to presence of various complex chemical substances of different compositions. Most of these compounds are synthesized in plants, as secondary metabolites. They are active ingredients and the main effective compounds in all medicinal plants. These active ingredients are chief constituents of the plants durgs, used in the form of ayurvedic and allopathic medicines. The plants drugs or herbal medicines offer conventional treatments, providing safe, well tolerated remedies for chronic illness.

These medicines have the ability to affect the human body systems. These effects are dependent on the chemical constituent's presents in the plants.

In the present work an attempt is made to present some interesting ethno medicinal observations recorded in Sangola division, Solapur district, Maharashtra, India. While carrying out the field work, help was taken from the traditional healers in the plants of medicinal values and information, as they are familiar with the plants around them. The findings of this study can provide useful leads for pharmacological conformation of these reported uses which might in time become useful for mankind.

Sangola taluka is the region under investigation is very rich in biodiversityconstitute the districts Solapur. The study of medicinal plants was practically neglected from this region. Hence, it was felt to undertake the study.

\section{MATERIAL AND METHOD}

The study of medicinal plants generally servey, collection of data and observation like this process were used. The study is based on the data collected on common plants of medicinal values in Sangola taluka, district Solapur, Maharashtra, India. The servey was conducted in selected region and the study was carried out with elder people of both men and women, chief of villege, vaidyas, herbal knowledgeable, and headmans. The methodology was adapted as described by Chadwick, Marsh and S. K. Jain. Structured questionaries, interviews, and partionaries observation were used to illustrate information from the resource person using the standard method. Also smpling method can be applied for detailed interviews were conducted with herbal specialist in the rural areas. At the time of study rural people shared his valuable information about the medicinal plants. All the data were collected in field on the basis of interviews with the traditional practitioners, men utilized of various medicinal plants in curing various ailments and were also taken more knowledgeable person for study of plants. Overall documentation the treatment pattern of various species were checked and confirmed. The specimens were collect and observe in their natural habitat and identified. Detail information was collected on the basis of health profile, social, economic and cultural aspects. Generally for the extraction of chemical constituent there are four methods are used. To extract chemical constituent from different organs and the tissue of medicinal plants these method are such as distillation, enfleurage $\&$ maceration, solvent extraction and expression.

Servey, collection of data and observation like this method are used to study of medicinal plants in rural area of sangola taluka. Out of the collection and servey made some of the specimens frequently occur that's named as Azadirachta indica Juss., Aloe vera Mills., Catheranthes roseus Don. and less number of species like Emblica officinales Gaertn., Casia fistula Linn. is observed. When servey of whole taluka is made there is found numbers of species of medicinal plants in different locality of the taluka which come under wild and local area of which only five species taken into consideration for the study. The name of the following species is Azadirachta indica Juss., Aloe vera Mills., Catheranthes roseus Don., Casia fistula Linn., and Emblica officinales Gaertn. were recorded and brought such above plants parts like root, bark, wood, stem, leaves, flowers, fruit and seed and with help of prior analytical methods recorded chemical constituents and apply for curing a various ailment and diseases such methods are utilized for the study of medicinal plants.

\section{RESULT AND DISCUSSION}

In this work five species has been taken into consideration for the study of medicinal plant which is vast use in concern with medicinal values to cure the various ailment and diseases. Name of some common plants like Azadirachta indica Juss., Aloe barbadense Mills., Catharanthus roseus Don., Casia fistula Linn. and Emblica officinales Gaertn. All this common plants found in both rural and urban areas of Sangola taluka, the name of places pericularly mention in the distribution of study area. All this medicinal plants discussd with respect to their english name, scientific name, vernacular name, source, family and distribution, chemical composition and uses. 


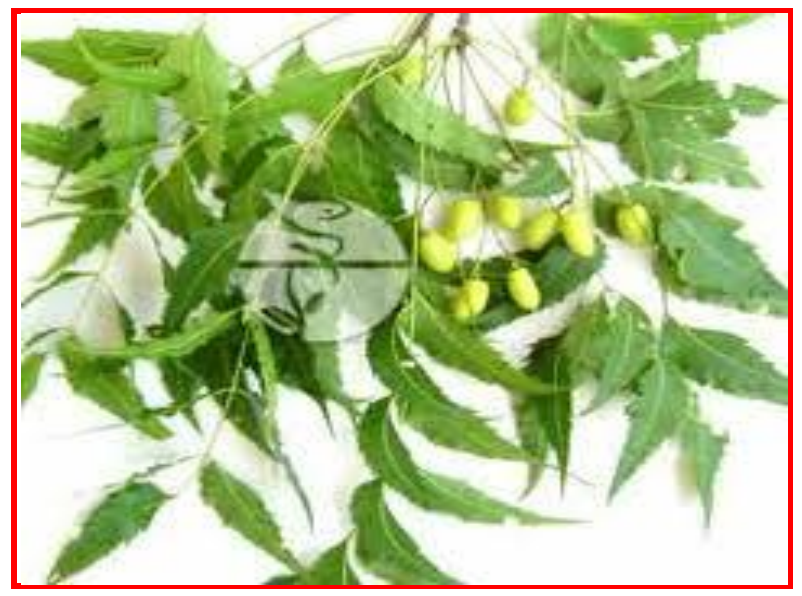

Azadirachta indica Juss.

1. Margosa tree

Scientific name: Azadirachta indica Juss.

Vernacular Name: Neem, Kadu-limb

Source: The leaves, bark, flowers, fruits and seeds are used as a drug

Family \& Distribution: Meliaceae, it is native of Burma but grown all over India. In Sangola taluka neem is found in large scale in rural and urban places. Some imporntant places like Narale, Sangola, Spinning mill, Hatid, Walegaon, Andhalgaon, Wasteland of Sangola, it is recorded in garden, School and Colleges, Akola and Mangewadi etc.

Chemical composition: The alkaloids are the main active principles. They are nimbin, nimbinin, nimbidine, nimbosterine and nimbectin etc. fatty acid present in the plant and seed contain 40 to $45 \%$ fixed oil

Uses: The leaves are carminative, expectorant, anthelmintic, diuretic and insecticidal properties. Fresh leaf juice with salt given for intestinal worms, jaundice, skin disease and malarial fever. The leaves are applied for boils, chronic ulcers, swelling and wounds. Bark is used for liver complaint, remove round worms. Gum is stimulant, demulcent tonic and used in debility. The tender twigs are chewed to maintain good dental hygiene. Flowers are used in debility. Fruit is effective for urinary diseases and leprosy. Seed oil used for skin diseases like eczema and scabies, preparation soap in industry. The paste of seed used for kill lice. The bark, gum, leaves, and seeds are used in scorpion sting. The dried leaves are used in to protect stored food grain.

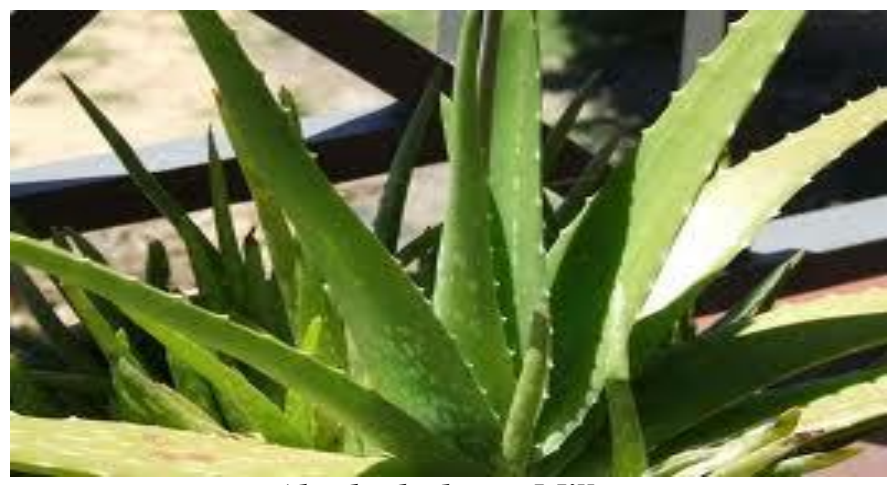

Aloe barbadenses Mills.

2. Aloe vera

Scientific Name: Aloe barbadenses Mills.

Vernacular Name: Korphad, Gritakumari

Source: Thick fleshy leaves ( Pulp, dried, juice) are used as a drug

Family \& Distribution: Liliaceae, it is native of West Indies or Mediterranean region. It grows wild in hot dry valleys of Western Himalayas and southern, Northern part of India. Sangola is the one of the drought region it is mainly distributed in every places in rural area some of the important places like Waki, Mahud, Chindepir, Rajuri, Sangola, Jawala and Gherdi. It is xerophytic plant.

Chemical composition: The main active principle present in Aloe is crystalline glucoside known as barbaloin, other constituent like resin and derivatives like emodin, chrysophanic acid, anthroquinones, emoclin, also it contain glucose, galactose, mannose and galacturonic acid with protein. The plant contain aloesone and aloesin. 
Uses: Aloe is chiefly used as purgative, abortificient, anthelmintic, blood purifier, cathartic, cooling, digestive and diuretic, inflammation, painful parts of the body. It is useful in burn, cold cough, jaundice, worms and piles. Aloe is used in preparation of vegetables, pickles, cosmetics, skin blemisars, help to grow new healthy tissue. It is used as hair tonic as it stimulates the growth of hair.

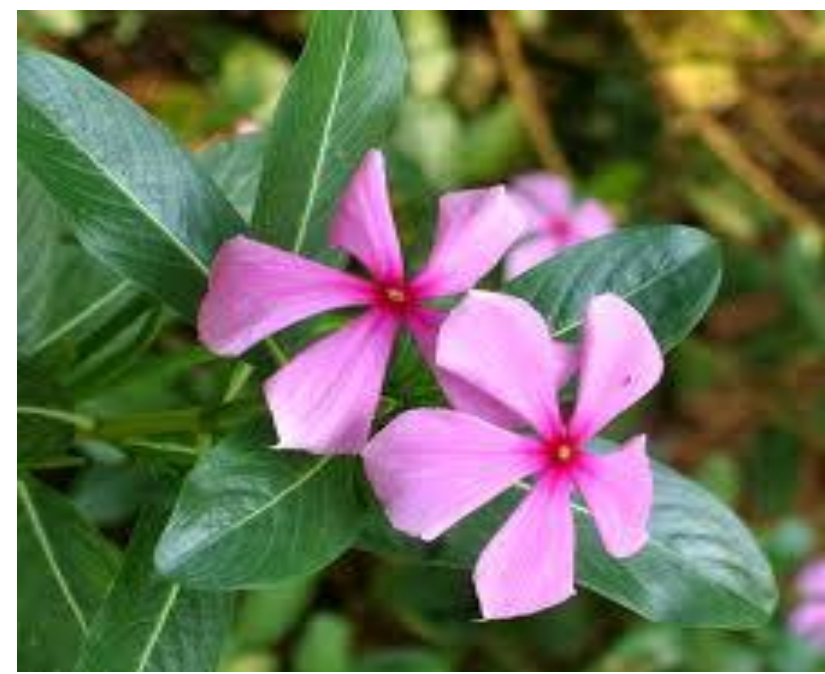

3. Periwinkle

Catharanthus roseus Don.

Scientific Name: Catharanthus roseus Don.

Vernacular Name: Sadaphuli, sadabahar

Source: The dried leaves and roots of this plant used as a drug

Family \& distribution: Apocynaceae, the plant is probably indigenous to Madagascar. It is cultivated in South Africa, West Indies, Srilanka, India, U.S.A., Europ and Australia as an ornamental plant. It is also cultivated for its medicinal properties, in the garden. In India, it is grown in Nilgiri, Kanyakumari and Kottayam etc. In Sangola it is distributed each and every waste land, domestic places and garden. Plant is obeserved in rural area like Wanichinchale, Medsingi, Walegaon, Kadlas, Sangola, and Andhalgaon.

Chemical composition: Catharanthus mainly consists of glycosides and alkaloids. The alkaloids are present in entire plant but they are found in more proportion in leaves and root. Some important alkaloids are vinblastine, vincristine, other alkaloids present in the plant are ajmalcine, serpentine, lochnerine, tetrahydroalstonine, vindoline, vindolinine and catheranthine.

Uses: It is used in hypotensive, antidibetic action, other dimer indole-indoline used for curing the anticancer activity. The alkaloids vincristine is highly active in treatment of childhood leukaemia. Vincristine proves effective in breast cancer and the leaves are used in diabetes.

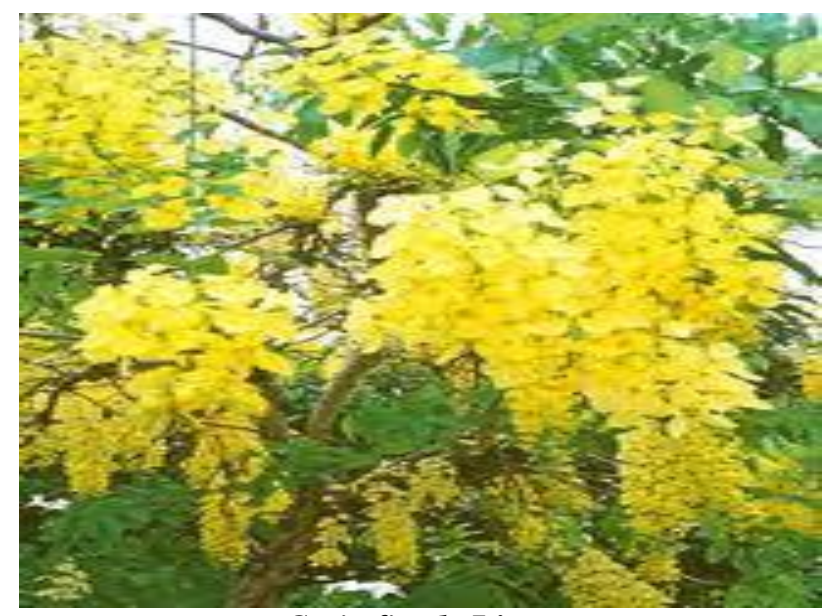

Casia fistula Linn.

4. Purging Casia

Scientific Name: Casia fistula Linn.

Vernacular Name: Bahwa, Amaltas.

Source: Pod and bark of this plant used as a drug. 
Family \& Distribution: Caesalpinaceae, this is an ornamental tree with yellow flowers found throughout India. Grow in valleys upto $1200 \mathrm{~m}$ in Himalayas. In Sangola region it is found in proper Sangola, spining mill Sangola and campus of Sangola college.

Chemical composition: 1-8 dihydroxyanthraquinone, Tryptamines , Fistucacidin(3,4,7,8,4,pentahydroxyflavan Oxyanthraquinone, Epincatechin, Procyanidin B2, Biflavanoids, Rhenin, Physcion, Kaempferol, Chrysophanol, Fistulin, Fistulic acid.

Uses: The sweet blackish pulp of the seedpod is used as a mild laxative. The wood is hard and heavy is used for cabinet and inlay work. Roots are astringent, cooling, purgative, febrifuge and tonic. It is useful in skin diseases, burning sensations and syphilis. Bark is laxative, anthelmintic, emetic, febrifuge, diuretic and depurative. It is useful in boils, leprosy, rignworms affection, colic, dyspepsia, constipation, diabetes, stranury and cardiac problems. Leaves are laxative, antiperiodic and depurative. It is useful in skin diseases, burning sensation, dry cough and bronchitis. Fruits are sweet, cooling, purgative, carminative, anti-inflammatory, diuretic and ophthalmic. It is used in flatulence, colic, dysentery, inflammations and intermittent fever. It is also used in cardiac disorders, strangury, opthalmopathy and general debility. Pulp form fruits called 'Casia pulp' is a well known laxative. Bark of tree is rich in tannins. Flowers are bitter, acrid, cooling, emollient, purgative and are useful in vitiated condition of pitta, burning sensation, leprosy, and skin diseases. It is also useful in cardiac disorders, intermittent fever and general debility.

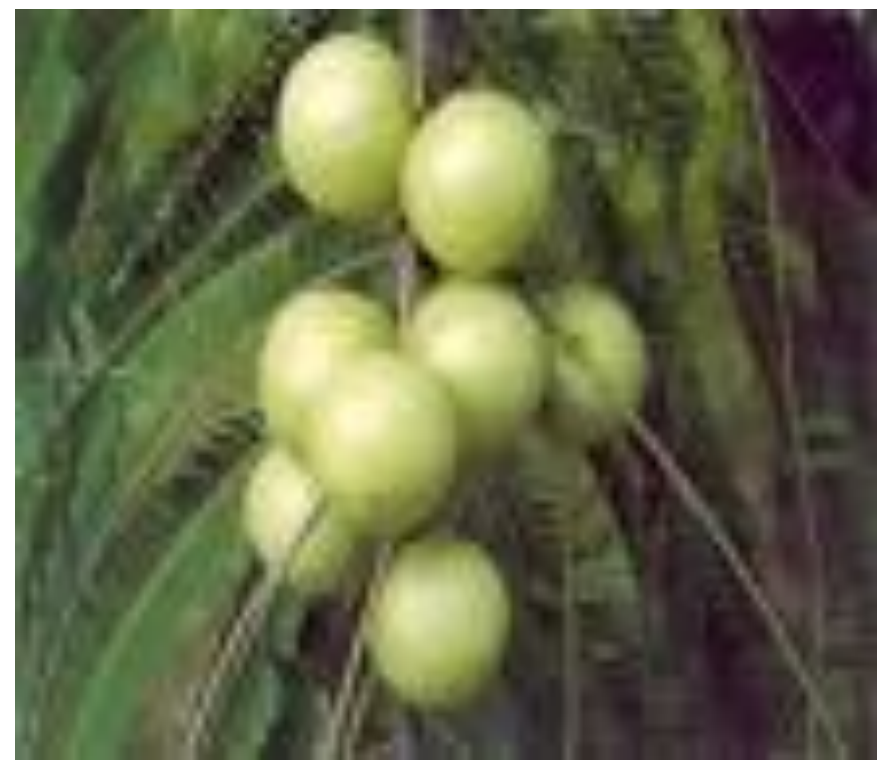

Emblica officinales Gaertn.

5. Emblic myrobalan, Indian Gooseberry

Scientific Name: Emblica officinales Gaertn.

Vernacular Name: Avala, Dongri Avala, Amla.

Source: Fresh and dried fruit.

Family \& Distribution: Euphorbiaceae, Emblica is a small genus of trees, native of India, Srilanka, Malaya and China. It is found in lacal area of Sangola like Watamabare, Hadid, Kole, Methwade, Spining mill, campus of Sangola college and Nazare.

Chemical composition: The fruit is the richest source of Vitimin C. The other imporntant constituents are gallic acid, tannic acid, gum, sugar, fat, phyllemblin, minerals Fe, P, Ca. Bark contain tannin and seeds contain fixed oil and essential oil.

Uses: Amla fruit which is acrid, cooling, refrigerant, diuretic and mild laxative. Fresh fruit used in intestine worms, pulp of fruit used in to cure the jaundice, anaemia, dyspepsia and scurvy. From this fruit famous ayurvedic tonic 'Chavanprash' and 'Triphala churn' is prepared. Dried fruit are used in haemorrhage (bleeding), diarrhea, dysentery, cough. It is used as laxative, headache, piles, liver. Seed applied in scabies and itching. Fruit juice is used in hair dye and seed oil and fruit juice are used in the preparation of hair oils and shampoos. Leave are used as a fodder. The fruit are also used in preparation of inks.

\section{ACKNOWLEGEMENT}

Authors are thankful to knowledge providers for providing valuable information, who has guide to me and gives moral support to do this work. The authors also wish to state that prior informed consent was taken from the knowledge providers as per his guidelines. 


\section{REFERENCES}

[1]. Mishra P. Ecology, Culture and Health: A Primitive Tribe, (Serials Publications, New Delhi), 2004.

[2]. Jain SK, Mudgal A. Handbook of Ethonobotany. Scientific Publishers, Jodhpur. 1999.

[3]. Chadwik DJ, Marsh J. Ethnobotany and the search for new Drugs. John Wiley and Sons, Chichester, U.K, 1994.

[4]. Martin G. Ethnobotany-A method manual. Chapman and Hall, London. 1995.

[5]. Rao VLN, Bharati K, Appalanaidu P, Naidu JM, Venkaiah M. Common plants of medicinal valuesin Kolam of Adilabad district, Andhra Pradesh. Int J Med Biomed Res 2012;1(2):111-118.

[6]. Levinson D. Encyclopedia of Cultural Anthropology, Henryholt and company, New York, 1996.

[7]. Acharya D, Shrivastava A (2008). Indiginous Herbal Medicine: Tribal Formulation and Tradinal Herbal Practices, Aviskars Publishers Distributor, Jaipur-India. ISBN 9788179102527. PP440.

[8]. Dike IP, Obembe OO(2012). Towards coservation of Nigerian medicinal plants. Journal of Medical Plants Research Vol. 6(19), pp. 3517-3521.

[9]. Patil CR, Pataskar PG, Nagraja TG, Sathe SS. A text book of Botany. Phadke Prakashan, Kolhapur, 1996,2004.

[10]. Pandey BP. Economic Botany. S. Chand and Company Ltd. 1990.

[11]. Dutta A, De B(1998). Seasonal variation in the content of sennosides and rhein in leaves and pods of Casia fistula. Indian J. Pharmacol. Sci. 60: 388-390.

[12]. Lohar DR, Chavan DD, Garg SP(1997): Phytochemical studies on Casia species of Indian Arid Zone Curr. Sci. 44:67.

[13]. Mahesh VK, Sharma R, Singh RS(1984): Anthraquinone and Kaemferol from Casia fistula sps. J. Xlat. Prod.47:733-751.

[14]. Modi FK, Khorana ML(1952): A study of Casia fistula Pulp. Indian J. Pharm. 4: 61-63.

[15]. Joseph Rock,(1884-1962) Kalaw tree (Taraktgenos Kurzii, Achariaceae), Chaulmoogla aril( for treatment of leprosy).

[16]. Richards Evans Schulte, from Harvard University. 